\title{
Crown structure of 25-year-old Siberian stone pine grafts from mother trees of different ages
}

\author{
Svetlana Velisevich ${ }^{1, *}$, Alexander Popov ${ }^{1,2}$, and Sergei Goroshkevich ${ }^{1}$ \\ ${ }^{1}$ Institute of Monitoring of Climatic and Ecological Systems SB RAS, 634055, Tomsk, 10/3 \\ Academichesky ave., Russia \\ ${ }^{2}$ Tomsk State University, 634050 Tomsk, 36 Lenina ave., Russia
}

\begin{abstract}
Inheritance of the age-specific traits of the Siberian stone pine crown structure by vegetative progeny was analyzed. Studies were carried out on 25-year-old grafts onto the same species seedlings as rootstocks. Scions for grafting were sampled from two groups of trees: young-mature (YM) and old growth (OG) trees in the southeast of the West Siberian Plain. The analysis of graft development showed that the YM trees had a significantly higher and thicker trunk, and their crowns were broader and denser due to a larger number of shoots. They multiplied by means of the branching feature due to the predominance of axes 2-3 branching orders. The OG trees formed small and transparent crowns that visually resembled separate branches from the upper parts of the crown of ontogenetically old trees. It was suggested that in the vegetative progeny of trees of a different ontogenetic state, the growth potential was epigenetically inherited.
\end{abstract}

\section{Introduction}

Experiments on clonal plantations of conifers have showed that the use of scions from ontogenetically mature donor trees does not allow obtaining vegetative progeny with a high growth rate. Foresters now use young donor trees in breeding for the growth rate [1]. However, the mechanisms underlying the phenomena of memory preservation in separated parts of plants is a subject of scientific discussion [2].

Scientists are interested in Siberian stone pine mainly as a tree producing pine nuts, but the influence of the donor tree's age on the grafts' development remains unknown. The purpose of this work is to study the influence of the donor tree's age on the vegetative growth of the grafts. We also wanted to assess the degree of epigenetic inheritance of agespecific features.

\section{Materials and methods}

\subsection{Object of study}

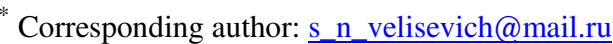


Scions for grafts were collected from Siberian stone pine trees in two sites located near

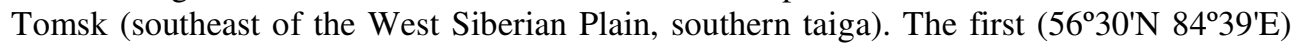
was a group of 220 -year-old old growth $(\mathrm{OG})$ trees. The second $\left(56^{\circ} 20^{\prime} \mathrm{N} 85^{\circ} 08^{\prime} \mathrm{E}\right)$ was a group of 30-year-old young-mature (YM) trees. Scions were grafted onto 5-year-old rootstocks. The experiment was carried out at the Kedr Field Station, which is managed by the Institute of Monitoring of Climatic and Ecological Systems, Russian Academy of Sciences $\left(56^{\circ} 13^{\prime} \mathrm{N} 84^{\circ} 51^{\prime} \mathrm{E}\right)$. To analyze the crown structure, one average branch was selected in each whorl of the stem, and then the total number of shoots was counted on each branch and multiplied by the number of such branches in the whorl and in each whole of the crown. The apical dominance was calculated from the ratio of the length of the stem to the length of the lateral branch. The crown transparency in the vertical projection was measured using software AutoCAD 2014 (Autodesk, USA).

\subsection{Statistical analysis}

The whole number of trees of each age group - 26 YM and 32 OG trees - served as a variation series in statistical calculations. The differences between the samples were estimated using the ANOVA F-test. Statistical data processing was carried out using the program Statistica 6.0.

\section{Results}

Large differences were found between YM and OG grafts (Table 1). YM grafts formed tall and thick trunks. Their crowns were much larger in size and superior to OG trees by the number of shoots and the number of branches per unit length of the trunk. Visually, the OG crowns were similar to individual branches from the crown top of an ontogenetically old tree. In OG trees, the crown was much lighter, with obvious signs of disintegration and isolation of individual large branches in the upper part (Fig. 1). This gave it a candelabra form, which is typical for the old age stage.

Table 1. Crown structure of grafts in different ontogenetic stages.

\begin{tabular}{|l|c|c|}
\hline \multicolumn{1}{|c|}{ Trait } & YM grafts & OG grafts \\
\cline { 2 - 3 } & Mean \pm error & Mean \pm error \\
\hline Stem height, m & $7.7 \pm 0.4^{*}$ & $5.6 \pm 0.1$ \\
\hline Stem diameter, cm & $19.1 \pm 1.0^{*}$ & $11.1 \pm 0.4$ \\
\hline Crown length, m & $7.5 \pm 0.5^{*}$ & $5.6 \pm 0.2$ \\
\hline Crown diameter, m & $4.5 \pm 0.3^{*}$ & $3.2 \pm 0.2$ \\
\hline Shoot number, pcs. & $5428 \pm 55.2^{*}$ & $2297 \pm 39.1$ \\
\hline $\begin{array}{l}\text { Branches per unit } \\
\text { stem length, pcs./m }\end{array}$ & $712 \pm 47.1^{*}$ & $370 \pm 56.7$ \\
\hline Crown transparency, \% & $11.6 \pm 1.76^{*}$ & $38.8 \pm 2.25$ \\
\hline
\end{tabular}

Significant differences between age variants for ANOVAs $(\mathrm{P} \geq 0.05)$ are indicated by asterisks.

In the structure of branching of YM trees there is a greater diversity in the order of branching (Fig. 2). They have a large proportion of axes of the 2 nd and 3rd orders, which has a positive effect on the increase in the density of the crown at this age. The crown of OG trees is less diverse in the participation of branches of higher branching orders. They have many axes of the 2 nd order and the percentage of skeletal branches of 1st order is relatively high. The part of axes of the 3rd order is much smaller than in YM trees. This type of branching contributes to the formation of an «openwork» crown in OG trees. 


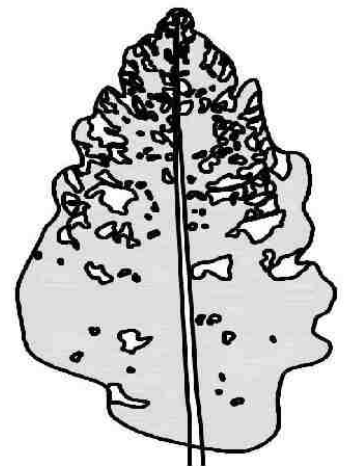

Young-mature

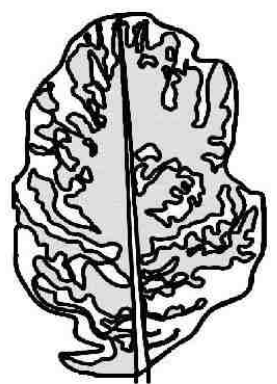

Old growth

Fig. 1. Crown shape and transparency.

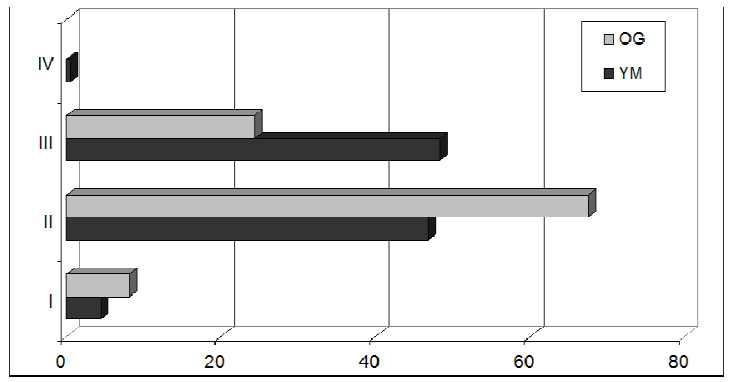

Fig. 2. Branching of YM and OG trees. The abscissa is the branching order, the ordinate is the proportion of shoots of different branching orders, \%.

\section{Discussion}

The problem of ontogeny regulation is far from resolved. The fact that the same traits (simple or complex) can be classified as epigenetically stable or labile complicates the knowledge of the mechanisms of ontogeny regulation. But most researchers agree that the branching pattern exhibits stable epigenetic inheritance [2-5]. Our results are consistent with their conclusions and show the inheritance of an age-specific branch pattern and the shape and density of the crown.

The generally accepted theory of ontogeny is based on the idea of the appearance, strengthening, and disappearance of the capacity for sexual reproduction, which shows itself in a successive change in the virgin, generative, and senile stages. That is, the growth changes in the ontogeny mainly for physiological reasons. This is due to changes in the root-leaf functional correlation, which gradually intensifies as the young tree grows and its vegetative power increases. Each level of this vegetative power corresponds to a new qualitative state of morphogenesis: genes responsible for these qualitatively new phenomena are activated or inactivated. This is assumed to be the essence of ontogenesis; therefore, any of the existing ways of dividing ontogeny into periods are based on qualitative changes in morphogenesis. Following our results, the successive change in the stages of ontogenesis, as the process of realizing the genetic development program, is characterized not by qualitative transformations in morphogenesis, but by growth potential: increase and decrease in vegetative capacity. Therefore, the growth potential is the main trait inherited by vegetative reproduction of trees of different ages. 
This work is supported by the Russian Science Foundation under grant no. 18-16-00058.

\section{References}

1. J. Kleinschmit, D.K. Khurana, H.D. Gerhold, W.J. Libby, Clonal Forestry II (Springer, Berlin, Heidelberg, 1993)

2. M.E. Day, M.S. Greenwood. Size- and Age-Related Changes in Tree Structure and Function (Springer, Netherlands, 2011)

3. M.S. Greenwood, M.E. Day, J. Schatz, Tree Physiol. 30, 459-468 (2010)

4. M.S. Greenwood, C.A. Hopper, K.W. Hutchison, Plant Physiol. 90, 406-412 (1989)

5. G.A. Ritchie, J.W. Keeley, Tree Physiol. 14, 1245-1259 (1994) 